\title{
Clinical profile and outcome of snake bite in children at a tertiary care centre in South India
}

\author{
Sanjay H R ${ }^{1}$, *Habeeb Ullah Khan ${ }^{1}$, Jaidev M D ${ }^{1}$, Pavan Hegde ${ }^{1}$
}

Sri Lanka Journal of Child Health, 2021; 50(4): 704-708

DOI: http://doi.org/10.4038/sljch.v50i4.9891

\begin{abstract}
Introduction: Snake bite is an important public health problem in the rural tropics, resulting in envenomation and death.

Objectives: To study the clinical profile of snake bite at a tertiary care centre in South India, estimate its case fatality rate and estimate the prevalence of complications in children with snake bite.
\end{abstract}

Method: This was a retrospective, observational descriptive record based study conducted in a Medical College in South India between May 2011 and April 2020.

Results: A total of 160 snake bite patient case records over the last 10 years were evaluated out of which signs of envenomation were seen in 65 cases. The male: female ratio was 1.8:1. Peak age group affected was 6 to 15 years. Lower limbs were the most common site of snake bite. Pain and swelling at the site of bite were the most common symptoms of envenomation. Cellulitis and coagulopathy were the most common complications seen in our study. Anti-snake venom (ASV) was used in 65 cases and the average ASV required in local and systemic envenomation was 5 and 20 vials respectively. There was one death during the study period.

Conclusions: Lower limbs were the most common site of snake bite. Pain and swelling at the site of bite were the most common symptoms of envenomation. Cellulitis and coagulopathy were the most common complications. The case fatality rate was $0.6 \%$.

(Key words: Snake bite, Anti-snake venom, Children)

${ }^{1}$ Father Muller Medical College, Mangalore, India

*Correspondence: habibkhans@fathermuller.in

https://orcid.org/0000-0001-9464-5966

(Received on 11 December 2020: Accepted after revision on 22 January 2021)

The authors declare that there are no conflicts of interest.

Personal funding was used for the project.

Open Access Article published under the Creative

Commons Attribution CC-BY@C (i) License

\section{Introduction}

Snake bite is an important public health problem in the rural tropics, resulting in envenomation and death. Of the 216 snake species in India, about 52 are poisonous ${ }^{1}$. The chief poisonous snakes in India are common cobra, king cobra, common krait, Russell viper, saw scaled viper, pit viper and sea snakes. Around 100,000 deaths due to snake bite are seen worldwide per year of which 35,000-50,000 deaths are from India ${ }^{2,3}$. Populations in these regions experience high morbidity and mortality because of poor access to health services and due to scarcity of anti-snake venom (ASV), which is the only specific treatment. As followed in many developing countries, traditional snake-bite remedies such as application of tourniquet, suctioning at the bite site, amputation of the bitten finger and application of herbal leaf extracts over the bite site may be important determinants of morbidity and mortality ${ }^{4}$. ASV available in India is polyvalent and is effective against the cobra, krait, Russell viper and saw scaled viper (the big four). It is ineffective against hump nosed pit viper, king cobra, sea snakes and other poisonous snakes. A significant number of children are bitten by snakes every year in our region. Majority of studies have been done on adult snake bite victims and only limited studies are available based on snake bite envenomation in children in our region. The clinical presentation and the complications of snake bite in children also differ significantly from adult snake bite victims.

\section{Objectives}

- $\quad$ To study the clinical profile of snake bite at a tertiary care centre in South India.

- To estimate the case fatality rate due to snake bite.

- To estimate the prevalence of complications in children with snake bite.

\section{Method}

A retrospective, observational, descriptive record based study was conducted over a period of 10 years (1st May 2011 to 30th April 2020) in a tertiary medical centre in South India. Patient information was obtained from medical case records which included parameters like age, gender, time of bite, site of bite, time of presentation to the hospital after the bite, clinical manifestations, complications, reaction to ASV and outcome of treatment. 
Ethical issues: The study protocol was approved by the Institutional Ethics Committee of Father Muller Medical College, Mangalore India (No FMIEC/CCM/351/2020). As this was a retrospective study, written informed consent was not possible.

Statistical analysis: The data were statistically analysed for mean, standard deviation, Chi square test by using SPSS software.

\section{Results}

Our study included 160 diagnosed cases of snake bite of which 104 were male and 56 were female. The male: female ratio was $1.8: 1$. Figure 1 is the study flow chart.

Majority ( $73 \%$ ) of children affected by snake bite were in the school going age group (6-15 years) as shown in figure 2.

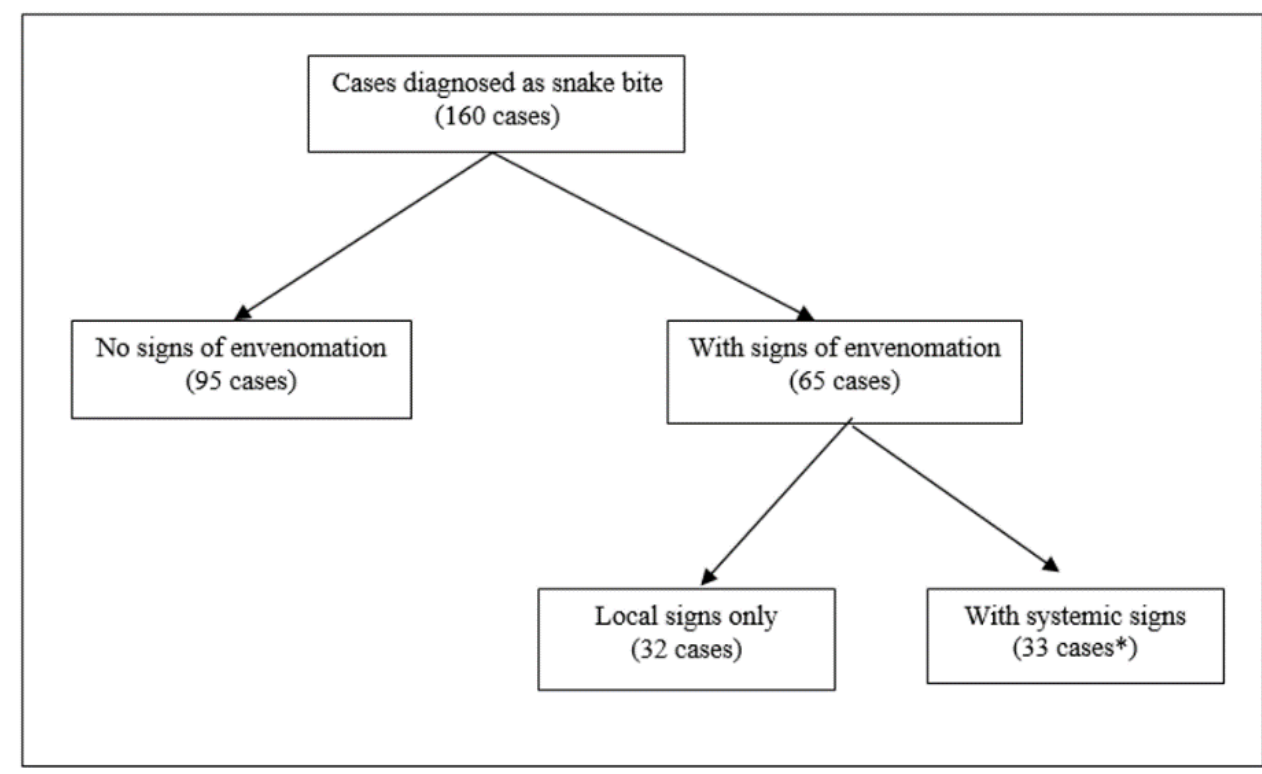

*All had local signs in addition

Figure 1: Study flow chart

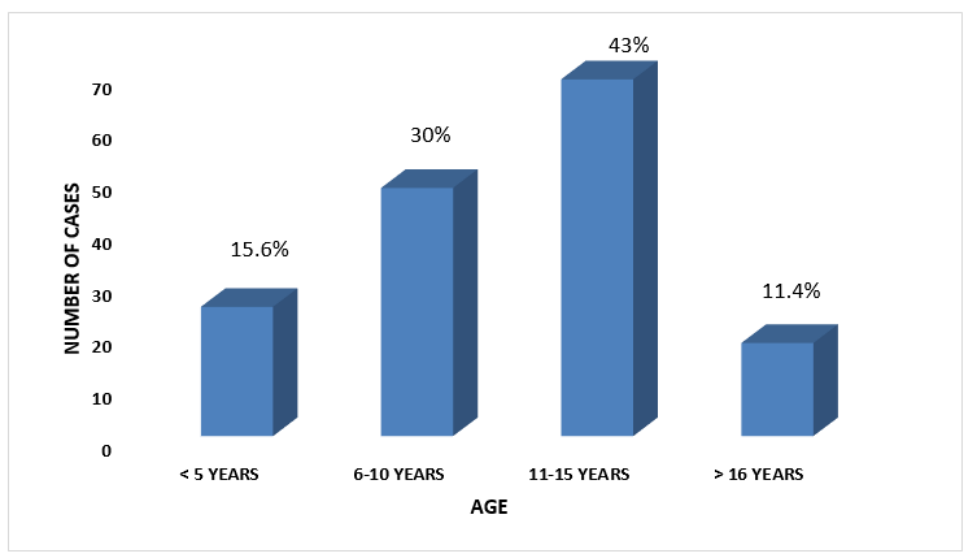

Figure 2: Age distribution of snake bite

Children from rural areas $(n=92)$ were more affected than urban children $(n=68)$. More than half the children $(n=89)$ were bitten in the daytime. All Krait bites were reported at night $(n=9)$. The types of snake bite seen in our study are shown in table 1.

In almost a quarter of cases, we were unable to identify the type of snake. The most common site of bite was the lower limb $(n=126)$ as shown in table 2 .
Table 1: Type of snake bite

\begin{tabular}{|l|c|}
\hline \multicolumn{1}{|c|}{ Type of snake } & Number (\%) \\
\hline Saw scaled viper & $23(35.3)$ \\
\hline Russell viper & $01(0.6)$ \\
\hline Cobra & $13(20.0)$ \\
\hline Krait & $09(13.8)$ \\
\hline Hump nosed pit viper & $03(04.6)$ \\
\hline Unidentified & $16(24.6)$ \\
\hline Total & $65(100.0)$ \\
\hline
\end{tabular}


Table 2: Site of snake bite

\begin{tabular}{|l|c|}
\hline \multicolumn{1}{|c|}{ Site of bite } & Number (\%) \\
\hline Upper limb & $33(20.6)$ \\
\hline Lower limb & $126(78.8)$ \\
\hline Multiple bites & $01(0.6)$ \\
\hline Total & $160(100.0)$ \\
\hline
\end{tabular}

Most of the cases $(n=138)$ were brought to the hospital within 6 hours of the bite. Pain $(100 \%)$ and oedema $(86.1 \%)$ were the common local effects and ptosis $(9.23 \%)$ was the most common neurological sign of envenomation as shown in Table 3.

Table 3: Clinical manifestation of envenomation

\begin{tabular}{|l|c|}
\hline \multicolumn{1}{|c|}{ Clinical feature } & Number (\%) \\
\hline Local signs & $56(86.1)$ \\
Oedema/swelling & $65(100.0)$ \\
Pain & $17(26.2)$ \\
Bleeding from bite site & \\
\hline Systemic signs & $01(01.53)$ \\
Diplopia & $01(01.53)$ \\
Dysphagia & $0(0)$ \\
Dysarthria & $06(09.23)$ \\
Ptosis & $04(06.15)$ \\
Respiratory distress & $04(06.15)$ \\
Haematuria & \\
\hline
\end{tabular}

The envenomation pattern in our study is shown in Table 4.

Table 4: Type of envenomation

\begin{tabular}{|l|c|}
\hline \multicolumn{1}{|c|}{ Type of envenomation } & n (\%) \\
\hline No envenomation & $95(59.4)$ \\
\hline Local envenomation only & $32(20.0)$ \\
\hline Local + Haemotoxic & $30(18.7)$ \\
\hline Local + Neurotoxic & $10(06.3)$ \\
\hline Haemotoxic only & $24(15.0)$ \\
\hline Neurotoxic only & $09(05.6)$ \\
\hline Local + Haemotoxic + Neurotoxic & $02(01.2)$ \\
\hline Neurotoxic + Haemotoxic & $01(0.6)$ \\
\hline
\end{tabular}

Average ASV required in local and systemic envenomation was 5 and 20 vials respectively. Table 5 shows the number of vials of ASV used.

Table 5: Number of vials of anti-snake venom used

\begin{tabular}{|l|c|}
\hline \multicolumn{1}{|c|}{ Number of vials } & Number (\%) \\
\hline $1-10$ & $38(58.5)$ \\
\hline $11-20$ & $21(32.3)$ \\
\hline$>20$ & $06(09.2)$ \\
\hline Total & $65(100.0)$ \\
\hline
\end{tabular}

In the 65 children showing signs of envenomation, 38 required less than 10 vials and only 6 required more than 20 vials of ASV.

In our study, $33.8 \%$ of cases developed cellulitis as a local complication and $36.9 \%$ developed venom induced consumption coagulopathy (VICC) as a systemic complication as shown in table 6 .
Table 6: Complications of snake bite

\begin{tabular}{|c|c|}
\hline Complication & n (\%) \\
\hline Local complications & \\
\hline Cellulitis & $22(33.8)$ \\
\hline Necrosis & $04(06.2)$ \\
\hline Ulceration & $03(04.6)$ \\
\hline Blister & $01(01.5)$ \\
\hline Systemic complications & \\
\hline Venom induced consumption & \\
\hline coagulopathy & $24(36.9)$ \\
\hline Myocarditis & $01(01.5)$ \\
\hline Neuroparalysis & $04(06.2)$ \\
\hline Acute renal failure & $02(03.0)$ \\
\hline
\end{tabular}

In our study, which included 160 cases of snake bite ( 65 with signs of envenomation), only one child died amounting to a case fatality rate of $0.6 \%$.

\section{Discussion}

This was a retrospective, observational descriptive record based study conducted over a period of 10 years in a tertiary medical centre in South India and included a total of 160 diagnosed cases of snake bite. In our study we found that snake bite was more commonly seen in male children with a male: female ratio of 1.8:1. Kshirsagar VY, et al ${ }^{5}$ and Kumar $\mathrm{AH}$, et $a l^{6}$ found a male: female ratio of 1.5:1 and 1.9:1 respectively in studies comprising 162 and 242 cases of snake bite. In our study, 95 (59.4\%) children had no signs of envenomation and $65(40.6 \%)$ children showed signs of envenomation. Whilst 32 cases developed only local signs, 33 had both local and systemic signs. A study done by Kumar AH, et $a l^{6}$, found that $80(33 \%)$ children had no signs of envenomation and $69(28.5 \%)$ children had only local envenomation.

In our study, out of 65 cases of envenomation, 23 $(35.3 \%)$ were identified as saw scaled viper bite, 13 $(20 \%)$ as cobra, $9(13.8 \%)$ as krait, $3(4.6 \%)$ as hump nosed pit viper, $1(0.6 \%)$ as Russell viper and the remaining 16 cases were unidentified. Sankar J, et $a l^{7}$ from Pondicherry identified saw scaled viper as the most common snake in their study while Jayakrishnan MP, et $a l^{8}$ found Russell viper as the most common snake found in Kozhikode ${ }^{8}$. In our study, we found that children in the age group of 615 years were more prone for snake bite. Kumar AH, et $a l^{6}$, Rao $\mathrm{KV}$, et $a l^{9}$ found similar vulnerability of children of school going age.

In our study, it was observed that lower limbs were the site of snake bite in $126(78.8 \%)$ children. This finding is a consistent feature seen in all studies done in children ${ }^{5-9}$. We would suggest that use of protective footwear and clothes would help in reducing the risk of snake bite envenomation. In 5 cases, people followed traditional practices like oral suctioning of blood from the site of bite in 3 cases and 2 cases applied ayurvedic medication at the site 
of the bite. Use of traditional remedies may cause delay in seeking medical attention and probably increase the risk of morbidity and mortality ${ }^{11}$. Local pain $(100 \%)$ and swelling $(86.1 \%)$ at the site of bite were the most common manifestations of snake bite with envenomation in our study. Kumaravel $\mathrm{K}$, et $a l^{10}$ found almost $87 \%$ of cases developed local pain and swelling at the site of the bite in their study.

In the present study, cellulitis $(33.8 \%)$ was the most common local complication and VICC (36.9\%) was the most common systemic complication of snake bite. Average number of days required to treat VICC was 5 days. Neuroparalysis was seen in $2.4 \%$ of children and $1.2 \%$ of children developed acute renal failure requiring dialysis. Myocarditis was documented in only one child and 4 children required fasciotomy for impending compartment syndrome. Rao KV, et $a l^{9}$ and Kumaravel $\mathrm{K}$, et $a l^{10}$ also found that cellulitis was the most common local complication of snake bite in children. Kumar AH, et $a l^{6}$ found that compartment syndrome $(14.5 \%)$, acute kidney injury $(6.7 \%)$ and VICC $(4.5 \%)$ were the common systemic complications of snake bite in children.

In $58.5 \%$ of cases, envenomation was successfully treated with less than 10 vials of ASV. Only 9.2\% children required more than 20 vials of ASV for treatment of coagulopathy. Pore SM, et al ${ }^{12}$, found that $48.6 \%$ of cases were treated with less than 10 vials and only $9.6 \%$ required more than 20 vials. Allergic reactions to ASV were seen in $28 \%$ of cases and they were treated as per WHO protocol. ASV was continued in them after the reactions subsided. All cases of hump nosed pit viper (HNPV) bites developed allergic reactions to ASV. This finding could be a clue to suspect HNPV bites. Bites of the HNPV had incoagulable blood for a mean of 6 days. As the existing ASV works only against cobra, krait, Russell viper and saw scaled viper (the big four), finding the particular component of the HNPV venom that makes blood incoagulable could be of major therapeutic importance in the field of anticoagulation. Luckily, HNPV are less venomous and can be managed without ASV.

We had only one death out of 160 cases of snake bite and the cause of death was multi-organ dysfunction following snake bite identified as common krait which required 4 days of ventilation. The case fatality rate in our study was $0.6 \%$. The case fatality rate in studies done by Kumar AH, et al ${ }^{6}$, Sankar J, et $a l^{7}$ and Rao KV, et $a l^{9}$ ranged from $1.5 \%$ to $13 \%$. Snake bite is a preventable cause of death if signs of envenomation are recognized early and if treatment is initiated at the earliest. Polyvalent ASV is effective against the common species of poisonous snakes in India and every effort should be made in making polyvalent ASV freely available. The availability of monovalent ASV in the future would potentially be helpful in reducing anaphylaxis and be more effective in neutralisation of venom.

\section{Conclusions}

Lower limbs were the most common site of snake bite. Pain and swelling at the site of bite were the most common symptoms of envenomation. Cellulitis and coagulopathy were the most common complications. The case fatality rate was $0.6 \%$.

\section{References}

1. Hansdak SG, Lallar KS, Pokharel P, Shyangwa P, Karki P, Koirala S. A clinicoepidemiological study of snake bite in Nepal. Tropical Doctor 1998; 28(4): 2236.

https://doi.org/10.1177/004947559802800 412

PMid: 9803844

2. Kasturiratne A, Wickremasinghe AR, de Silva N, Gunawardena NK, Pathmeswaran A, Premaratna R, Savioli L, Lalloo DG, de Silva HJ. The global burden of snakebite: a literature analysis and modelling based on regional estimates of envenoming and deaths. PLoS Medicine 2008; 5(11): e218. https://doi.org/10.1371/journal.pmed.0050 218

PMid: 18986210 PMCid: PMC2577696

3. World Health Organization. Guidelines for the clinical management of snake bites in the South-East Asia Region. Available from:

https://apps.who.int/iris/bitstream/handle/ 10665/205171/B0241.pdf;sequence $=1$

4. Newman WJ, Moran NF, Theakston RD, Warrell DA, Wilkinson D. Traditional treatments for snake bite in a rural African community. Annals of Tropical Medicine and Parasitology 1997; 91(8): 967-9.

https://doi.org/10.1080/00034983.1997.11 813228

PMid: 9579220

5. Kshirsagar VY, Ahmed M, Colaco SM. Clinical profile of snake bite in children in rural India. Iranian Journal of Pediatrics 2013; 23(6): 632.

6. Kumar AH, Kariyappa M, Vinutha GN. Clinico-epidemiological profile of snake bite in children in a tertiary care centre: a hospital based study. International Journal 
of Contemporary Pediatrics 2017; 5(1): 124-8.

https://doi.org/10.18203/23493291.ijcp20

175572

7. Sankar J, Nabeel R, Sankar MJ, Priyambada L, Mahadevan S. Factors affecting outcome in children with snake envenomation: a prospective observational study. Archives of Disease in Childhood 2013; 98(8): 596-601.

https://doi.org/10.1136/archdischild-2012303025

PMid: 23716133

8. Jayakrishnan MP, Geeta MG, Krishnakumar P, Rajesh TV, George B. Snake bite mortality in children: beyond bite to needle time. Archives of Disease in Childhood 2017; 102(5): 445-9.

https://doi.org/10.1136/archdischild-2016311142

PMid: 27806970

9. Rao KV, Ramesh G, Acharya A. Clinicoepidemiology, clinical profile and outcome of venomous snake bite in children in Konaseema region of Andhra Pradesh, India. International Journal of Contemporary Pediatrics 2019; 6(2): 625. https://doi.org/10.18203/23493291.ijcp20 190700

10. Kumaravel K, Ganesh J. A study on the clinical profile of children with snake envenomation in a tertiary referral centre at Dharmapuri, Tamilnadu, India. International Journal of Research in Medical Sciences 2016. Corpus ID. 78545167.

11. Newman WJ, Moran NF, Theakston RD, Warrell DA, Wilkinson D. Traditional treatments for snake bite in a rural African community. Annals of Tropical Medicine and Parasitology 1997; 91(8): 967-9.

https://doi.org/10.1080/00034983.1997.11 813228

PMid: 9579220

12. Pore SM, Ramanand SJ, Patil PT, Gore $\mathrm{AD}$, Pawar MP, Gaidhankar SL, et al. Ghanghas RR. A retrospective study of use of polyvalent anti-snake venom and risk factors for mortality from snake bite in a tertiary care setting. Indian Journal of Pharmacology 2015; 47(3): 270. https://doi.org/10.4103/0253-7613.157117 PMid: 26069363 PMCid: PMC4450551 